\title{
Propargylic Alcohols as Three-Carbon Synthons in a Rhodium-Catalyzed Het- eroannulation via a Merged C-H Functionalization and Cascade Cyclization Process
}

\author{
Prajyot Jayadev Nagtilak and Manmohan Kapur*
}

Department of Chemistry, Indian Institute of Science Education and Research Bhopal, Bhopal Bypass Road, Bhauri, Bhopal 462066, Madhya Pradesh, India

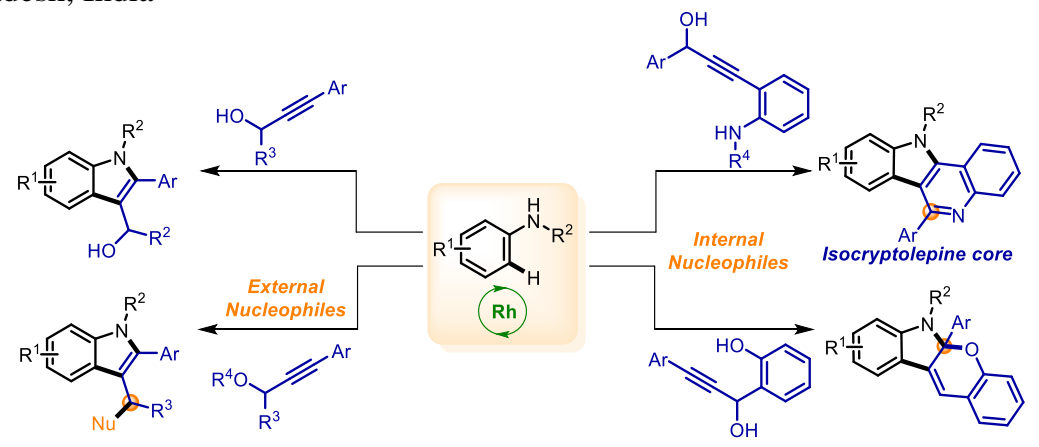

\begin{abstract}
:
We report herein, an unprecedented reactivity of propargyl alcohols as a "Three-Carbon Synthon" in the synthesis of core structures of isocryptolepine, $\gamma$-carbolines, dihydrochromeno[2,3-b]indoles and diindolylmethane's (DIM) derivatives. The transformation involves a rhodium(III)-catalyzed $\mathrm{C}-\mathrm{H}$ functionalization, heteroannulation of indoles followed by cascade cyclization with external as well as internal nucleophiles to afford diverse products. The reaction features highly effective transformations involving two $\mathrm{C}-\mathrm{C}$, two $\mathrm{C}-\mathrm{N}$ and two $\mathrm{C}-\mathrm{O}$ bonds, leading to the formation of a variety of molecular frameworks that are a part of several biologically active natural products.
\end{abstract}

The potential of a cascade process lies in making complex molecular frameworks via several transformations in one stroke, starting with a simple substrate with predetermined functionality. The development and execution of new cascade processes is a challenging aspect in organic chemistry. It brings with it, novelty along with improved practical efficiency, and an aesthetic appeal to synthetic planning. ${ }^{1}$ This is because cascade methodologies are atom- and step-economical, in the same sense being economical in terms of time, labor, and generation of waste materials too. Therefore, these cascade methodologies have captivated the attention of organic chemists, resulting in them being utilized in the synthesis of several biologically relevant heterocycles. $^{2}$

Tricyclic scaffolds incorporating the indole framework find widespread application in bioscience, medicine, and organic chemistry. Isocryptolepine (Figure 1), possesses the g-carboline core, which is present in many natural products, was isolated from the roots of the West African plant Cryptolepis sanguinolena. It shows diverse biological activities, comprising anti-inflammatory, anti-malarial, anti-plasmodial, antitumor and neuropharmacological properties. Along with $g$-carbolines, chromeno[2,3-b] indoles and diindolylmethanes show potent applications in the medical domain (Figure 1). ${ }^{3}$ The intriguing pharmaceutical potential of this molecular framework prompted us to design a new synthetic route by merging $\mathrm{C}-\mathrm{H}$ activation and a cascade cyclization.

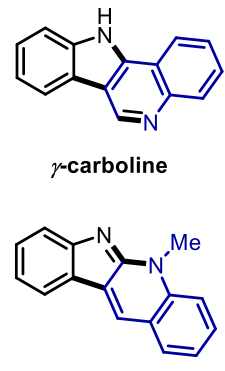

Neocryptolepine
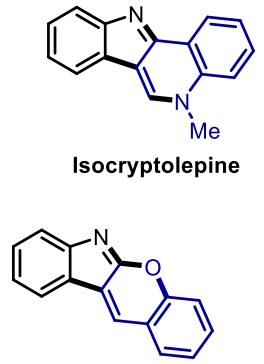

chromeno[2,3-b]indole
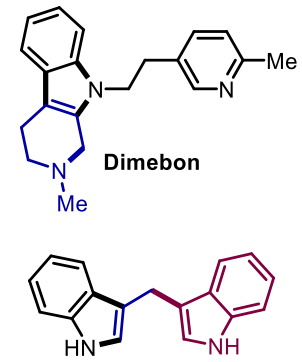

3,3'-Diindolylmethane
Figure 1. Selected examples of molecular frameworks possessing fused indole skeletons.

In the recent years, propargyl alcohols have emerged as unique coupling partners in $\mathrm{C}-\mathrm{H}$ functionalization reactions to achieve the rapid construction of complex molecular frameworks. ${ }^{4} \mathrm{Co}-$ ordination of the hydroxy group of the propargyl alcohol with 
the transition metal catalyst in the metallacycle leads to varied reactivity, chemo- and regioselectivity of the functionalization. ${ }^{5}$ Thus, propargyl alcohols can switch reactivities between being two-carbon synthons and very rarely as one-carbon synthons. (Scheme (1a)). ${ }^{6,7}$ Upon C-H functionalization, depending upon the reaction pathway that is then followed, the process leads to diverse products. ${ }^{8} \mathrm{We}$ report herein an unprecedented $\mathrm{C}-\mathrm{H}$ functionalization of propargyl alcohols as a three-carbon synthon with the anilide as a weakly-coordinating directing group (Scheme 1(c)).

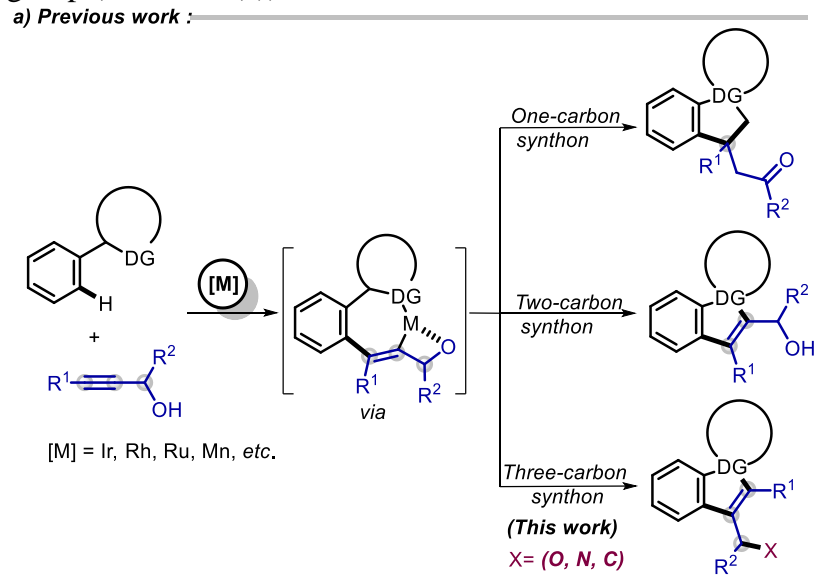

b) Propargyl alcohol as three carbon synthon:
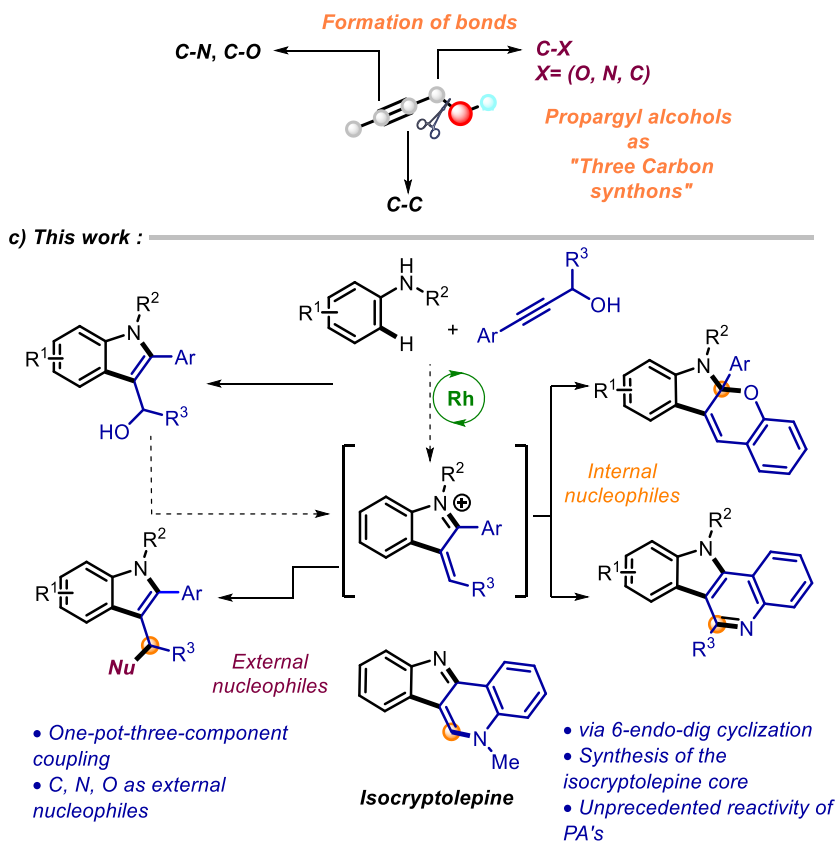

Scheme 1. Various reactivity modes for propargylic alcohols in $\mathrm{C}-\mathrm{H}$ functionalization.

Literature survey discloses that the design of heteroannulation of indoles with propargylic alcohols via merging $\mathrm{C}-\mathrm{H}$ activation and cascade cyclization sequences, has been limited and rather challenging, probably due to the problems associated with the self-cyclization and rearrangement reactions of propargyl alcohols. We have successfully designed an efficient method that provides highly diversified scaffolds in minimum numbers of steps, a new system in which we are able to switch the reactivities between these substrates to lead to important classes of tricyclic natural product scaffolds. Another highlight of the present work is the ability of the transformation to show unique selectivity with primary as well as secondary propargylic alcohols. This selectivity is rather rare and has been mostly demonstrated with tertiary propargylic alcohols only.

Considerable literature is available with activated propargylic alcohols, we instead sought to utilize unactivated alcohols for our coupling reaction. Upon extensive optimization (see the Supporting Information for details), the desired transformation was found to work best with the following conditions: [Cp* $\left.\mathrm{RhCl}_{2}\right]_{2}(2 \mathrm{~mol} \%), \mathrm{AgSbF}_{6}(6 \mathrm{~mol} \%), \mathrm{AgOAc}$ (2.0 equiv.) in ${ }^{t} \mathrm{BuOH}$ as the solvent. AgOAc was more effective than $\mathrm{Cu}(\mathrm{OAc})_{2}$ and others. ${ }^{t} \mathrm{BuOH}$ was found to be the best solvent for this reaction when compared to other polar and non-polar solvents. Other catalytic systems using ( $\mathrm{Pd}, \mathrm{Ru}, \mathrm{Ir}, \mathrm{Co}$ and $\mathrm{Mn}$ ) did not yield the desired transformation as effectively as the Rhcatalyst. With the optimized condition in our hand, we sought to explore the versatility of the transformation (Table 1).

Table 1. Substrate Scope for Indoles with Anilides and Propargyl Alcohols.

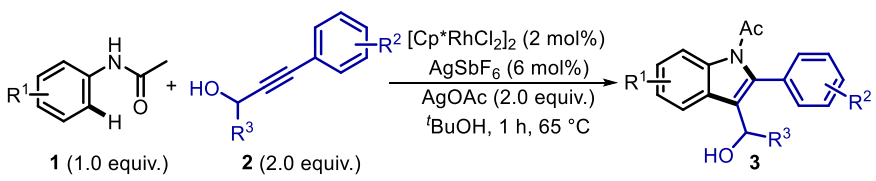

Substrate scope with primary and secondary propargylic alcohols:
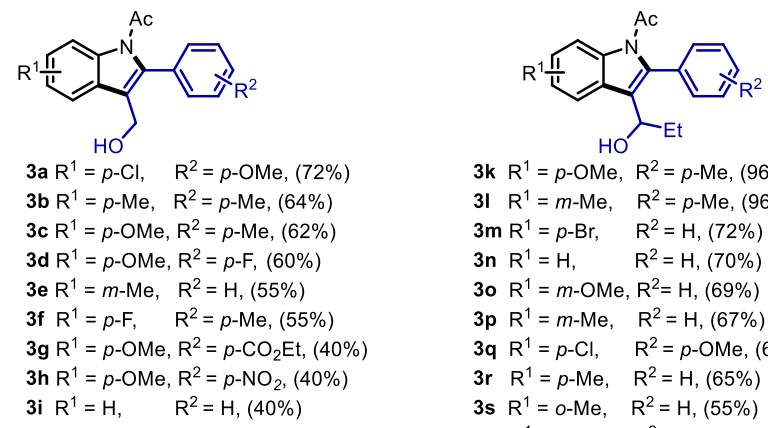

3k $\mathrm{R}^{1}=p$-OMe, $\mathrm{R}^{2}=p-\mathrm{Me},(96 \%)$

3I $\mathrm{R}^{1}=m-\mathrm{Me}, \quad \mathrm{R}^{2}=p-\mathrm{Me},(96 \%)$

$3 \mathrm{R}^{1}=p-\mathrm{Br}, \quad \mathrm{R}^{2}=\mathrm{H},(72 \%)$

3n $\mathrm{R}^{1}=\mathrm{H}, \quad \mathrm{R}^{2}=\mathrm{H},(70 \%)$

3o $\mathrm{R}^{1}=m-\mathrm{OMe}, \mathrm{R}^{2}=\mathrm{H},(69 \%)$

3p $\mathrm{R}^{1}=m-\mathrm{Me}, \quad \mathrm{R}^{2}=\mathrm{H},(67 \%)$

3q $\mathrm{R}^{1}=p-\mathrm{Cl}, \quad \mathrm{R}^{2}=p-\mathrm{OMe},(65 \%)$

3r $\quad \mathrm{R}^{1}=p-\mathrm{Me}, \quad \mathrm{R}^{2}=\mathrm{H},(65 \%)$

3s $\mathrm{R}^{1}=\mathrm{o}-\mathrm{Me}, \quad \mathrm{R}^{2}=\mathrm{H},(55 \%)$

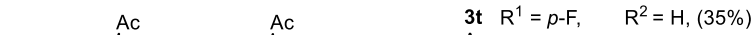

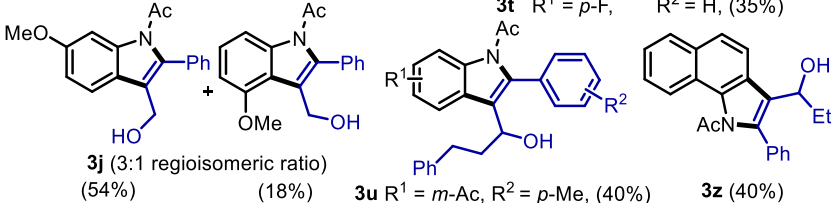

Substrate scope with tertiary propargylic alcohols:
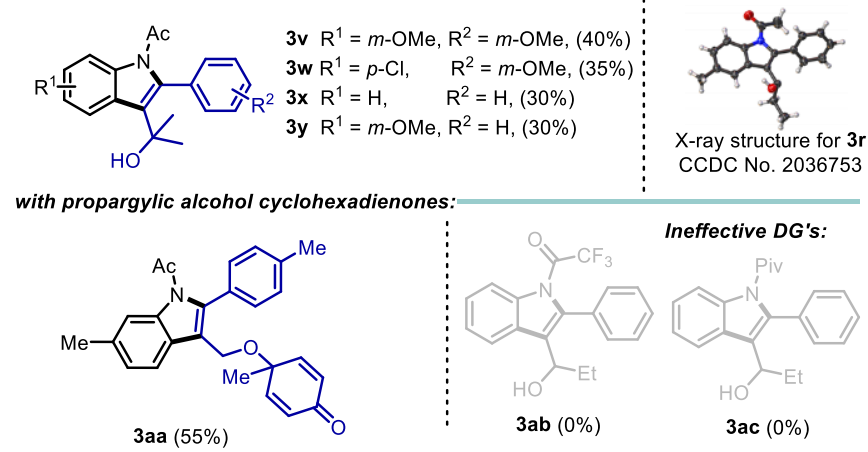

Most of the anilides and propargyl alcohols worked well with high chemo- and regioselectivity, with good functional group tolerance and the site selectivity remained intact in all the substrates scanned. The reaction worked very well with primary and secondary propargylic alcohols. The reaction with tertiary propargylic alcohols was only moderately successful and this could most probably be attributed to steric effects. Electronic factors were well-tolerated in this transformation although sluggish rates were observed for electron-withdrawing substituents 
Table 2. Substrate Scope with external nucleophiles.

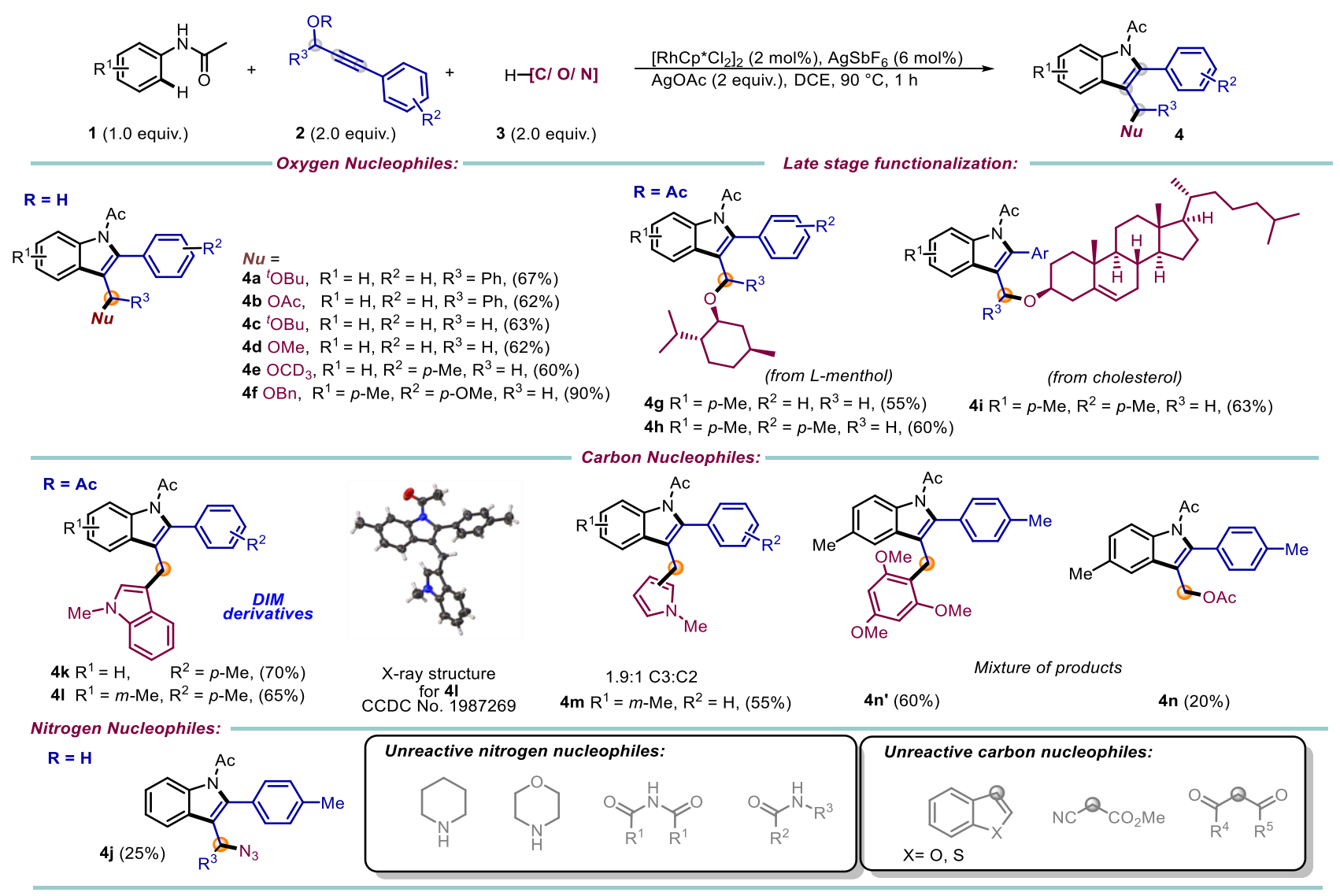

(3g, 3h, 3t, 3u, Table 1). In the case of $m$-methoxy acetanilide, a mixture of regioisomeric products was expectedly obtained (3j, Table 1). The regioselectivity of the indole product was confirmed by X-ray crystallography of 3r. Other directing groups like the pivaloylanilide and trifluoroacetanilide failed to yield the desired transformation which could be attributed to the steric effects of pivaloylanilide (3ab) and poor coordination ability of the trifluoroacetanilide (3ac, Table 1).

An interesting observation resulted when the reaction was prolonged beyond the completion of the annulation. The $-\mathrm{OH}$ group in $\mathbf{3}$ was displaced by $-\mathrm{O}^{t} \mathrm{Bu}$ group (4a, Table 2 ). This prompted us to check if the reaction could be generalized with a variety of nucleophiles in DCE (Table 2). By changing the solvent system to a non-nucleophilic solvent like DCE, the acetate substituted product was observed (4b, Table 2). A variety of $O$-nucleophiles were screened (4c-4f, Table 2) resulting in products in good to moderate yields. Furthermore, the versatility of established one-pot, three component protocol was successfully demonstrated by its application in the late-stage functionalization. L-menthol (4g-h, Table 2) and cholesterol (4i, Table 2) were found as potent $O$-nucleophiles to generate desired products with acceptable yield. Unfortunately for us, $N$-nucleophiles had very limited success and in only one case, the product

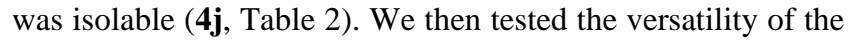
reaction with carbon nucleophiles using activated propargyl alcohols. To our delight, indoles, pyrroles and 1,3,5 trimethoxybenzene all resulted in products in good to moderate yields (4k-4n, Table 2), although in the case of $\mathbf{4 n}$, the acetate competed with trimethoxybenzene to afford a mixture of products. The potency of the nucleophile plays a key role in the formation of the desired product. Thus, $O$-nucleophiles (4a-f, Table 2) worked well with unactivated propargyl alcohols whereas soft nucleophiles (4k-n, Table 2) needed activated propargyl alcohols. For reasons not clear, the reaction did not work when furans, thiophenes and cyclic amines were employed as nucleophiles, in these cases the displacement of the $-\mathrm{OH}$ or the acetate from the indole was not observed.

After this interesting outcome resulting from external nucleophiles, we sought to explore the heteroannulation with internal nucleophiles. We thus designed propargylic alcohols bearing potentially reactive internal nucleophiles at the various positions. To initiate our study, we incorporated an $\mathrm{N}$-acetyl group (2, Table 3 ) on the phenyl ring for an internal cyclization. This was truly challenging, since these types of alkyne coupling partners tend to undergo self-cyclizations as well as rearrangements in the presence of transition metals or Brønsted acids. ${ }^{10}$

After an extensive screening of various catalyst systems, we found that the Rh-catalyst ( $4 \mathrm{~mol} \%$ ) in $\mathrm{DCE}$, at $90{ }^{\circ} \mathrm{C}$, was the best combination for obtaining the desired product. Under these conditions, only a trace amount of the Meyers-Schuster rearranged product was observed. Electron-donating and withdrawing substituents on both the aryl rings resulted in moderate yields (5a-e, Table 3). The regioselectivity was confirmed by $\mathrm{X}$-ray crystal structure of compound 5a (Table 3). We thus established an unprecedented domino-approach in achieving indolo[3,2-c]quinolines (5, Table 3 ) in a one-pot fashion where the $\mathrm{C}-\mathrm{H}$ activation predominates over the rearrangement or self-cyclization.

To further explore this chemistry, we designed hydroxyphenyl propargyl alcohols (2, Table 4$)$ to achieve an internal cyclization. Normally, propargyl alcohols of this type are benzofuryl carbene precursors, arising from the dual catalysis of the acid and the transition metal. ${ }^{9 \mathrm{a}, 10}$ To our delight, instead of this reactivity, we obtained the desired product via a 6-exo-trig cyclization, with the generation of quaternary centers. We did not observe any self-cyclization or by-products arising from 
rearrangements. The regioselectivity was confirmed by the $\mathrm{X}$ ray crystal structure of compound $\mathbf{6 a}$ (Table 4). This is a novel approach towards the synthesis of dihydrochromenoindoles in a single step, where the initial $\mathrm{C}-\mathrm{H}$ activation is followed by a cascade heteroannulation.

Table 3. Substrate Scope with internal $N$-nucleophiles
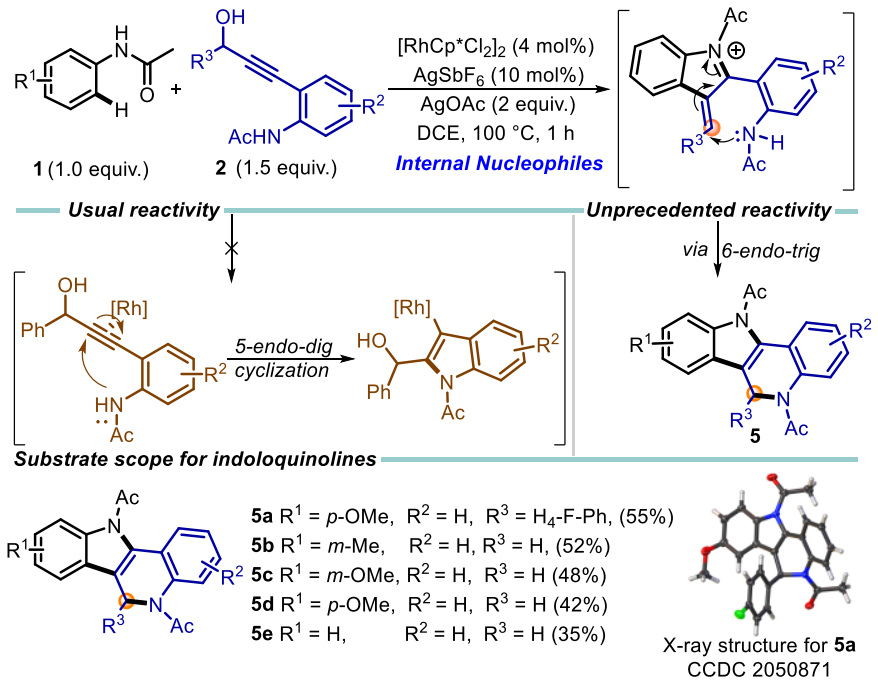

To further highlight the synthetic application of this methodology, the indoloquinolines that were synthesized (5, Table 3 ), were aromatized with DDQ to yield $\gamma$-carbolines (7, Table 5) which on $N$-deacylation and subsequent $N$-methylation ${ }^{11}$ led to isocryptolepine derivatives (9, Table 5), in acceptable yields. We were thus able to develop a new approach to achieve isocryptolepine derivatives in a minimum number of steps. ${ }^{3 a}$

Table 4. Substrate Scope with internal $O$-nucleophiles

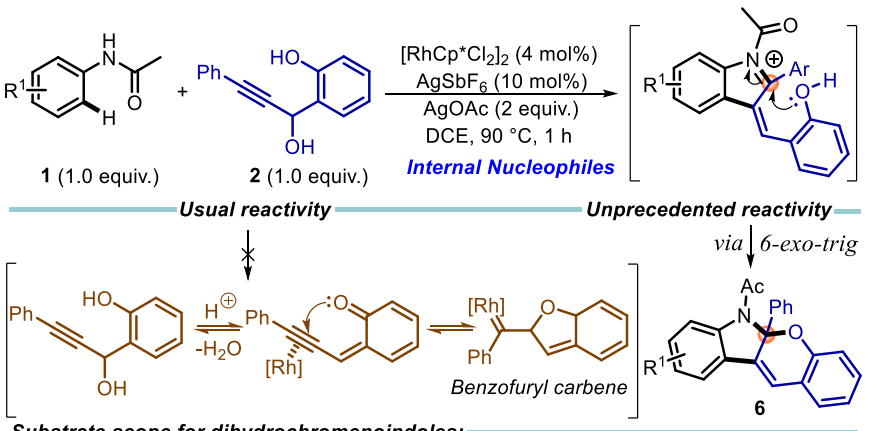

Substrate scope for dihydrof

6a $(40 \%)$

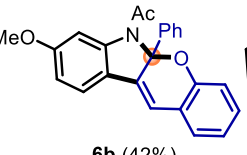

6b $(42 \%)$

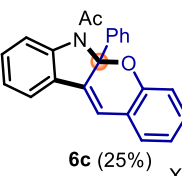

6c $(25 \%)$

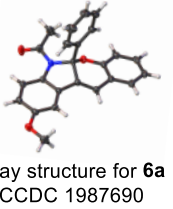

To achieve mechanistic insights into the transformation, various control experiments were carried out (Scheme 2). To check for the reversibility of the $\mathrm{C}-\mathrm{H}$ bond activation, the reaction was performed with added $\mathrm{D}_{2} \mathrm{O}$, resulting in significant amount of deuteration at the ortho positions of the recovered anilide (Scheme 2A). This indicated that the $\mathrm{C}-\mathrm{H}$ activation was a reversible process. This was also confirmed by the $\mathrm{D}-\mathrm{H}$ exchange experiment (Scheme 2c) in which a significant loss of the deuterated label was observed when the reaction was carried out in ${ }^{t} \mathrm{BuOH}$. Subsequently, to investigate whether the $\mathrm{C}-\mathrm{H}$ metallation step was rate-limiting, studies were conducted to check for a kinetic isotope effect. Parallel reactions indicated that the
$\mathrm{C}-\mathrm{H}$ bond cleavage was the rate-limiting step $\left(k_{\mathrm{H}} / k_{\mathrm{D}}=2.13\right)$, however competition reactions indicated otherwise $\left(k_{\mathrm{H}} / k_{\mathrm{D}}=\right.$ 1.10) (Scheme 2B). However, due to the reversibility in the protic solvent, the KIE studies via the parallel reaction seem more reliable.

Table 5. Synthesis of Isocryptolepine Derivatives
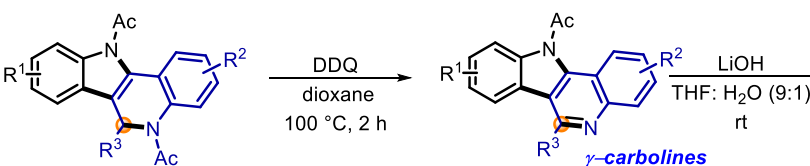

5b $\mathrm{R}^{1}=m-\mathrm{Me}, \mathrm{R}^{2}=\mathrm{H}, \mathrm{R}^{3}=\mathrm{Ph}$

$5 a \mathrm{R}^{1}=p-\mathrm{OMe}, \mathrm{R}^{2}=\mathrm{H}, \mathrm{R}^{3}=4-\mathrm{F}-\mathrm{Ph}$ $7 \mathbf{a} \mathrm{R}^{1}=m-\mathrm{Me}, \mathrm{R}^{2}=\mathrm{H}, \mathrm{R}^{3}=\mathrm{Ph},(70 \%)$
$7 \mathbf{b} \mathrm{R}^{1}=p-\mathrm{OMe}, \mathrm{R}^{2}=\mathrm{H}, \mathrm{R}^{3}=4-\mathrm{F}-\mathrm{Ph},(30 \%)$

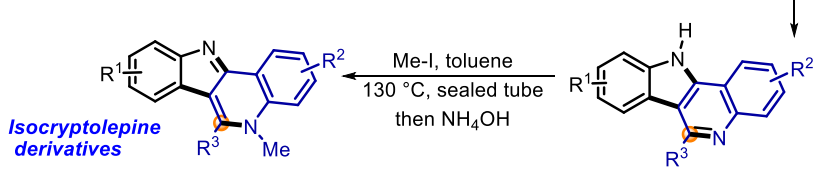

8a $\mathrm{R}^{1}=m-\mathrm{Me}, \quad \mathrm{R}^{2}=\mathrm{H}, \mathrm{R}^{3}=\mathrm{Ph},(88 \%)$

9a $\mathrm{R}^{1}=m-\mathrm{Me}, \quad \mathrm{R}^{2}=\mathrm{H}, \mathrm{R}^{3}=\mathrm{Ph},(80 \%)$

8b $\mathrm{R}^{1}=p-\mathrm{OMe}, \mathrm{R}^{2}=\mathrm{H}, \mathrm{R}^{3}=4-\mathrm{F}-\mathrm{Ph},(90 \%)$

A control experiment was carried out to check for the role of the $-\mathrm{OH}$ functionality, by employing the acetylene lacking the propargylic - $\mathrm{OH}$ and by using a propargyl ether (Scheme $2 \mathrm{C}$ ). The fact that the same regioselectivity was obtained for the alkyne indicated that the regioselectivity in migratory insertion was catalyst driven and the - $\mathrm{OH}$ group in all probability may not have a role to play in the selectivity process.

Scheme 2. Control Experiments and Kinetic Isotope Effect (a)

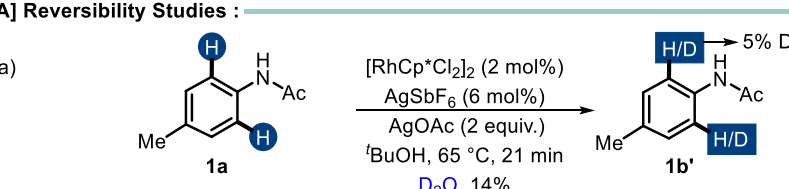

(b) $\mathrm{D}_{2} \mathrm{O}, 14 \%$

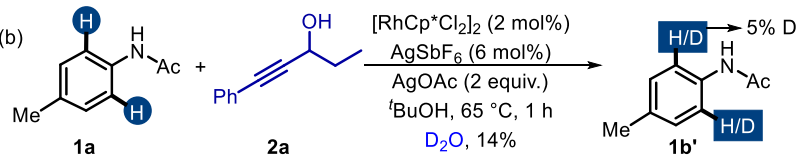

(c)
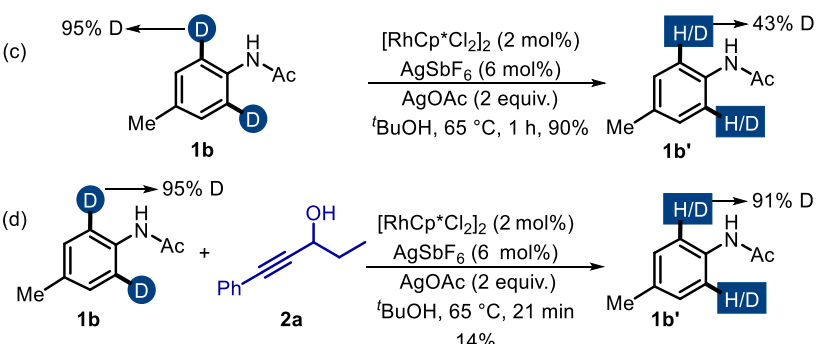
$14 \%$

B] Studies to determine Kinetic Isotope Effect :

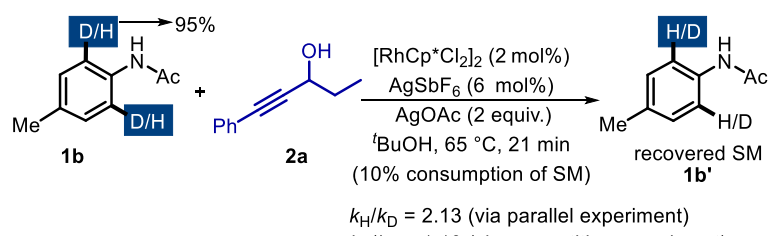
$k_{H} / k_{D}=1.10$ (via competitive experiment)

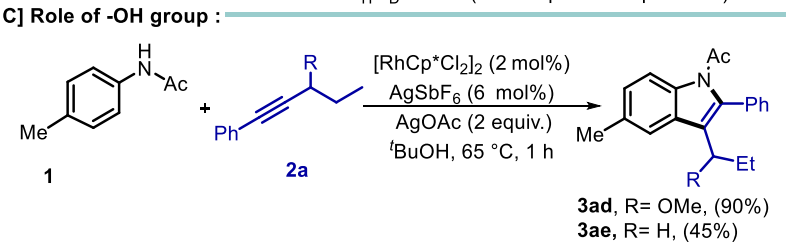


Based on the mechanistic investigations and previous literature reports, ${ }^{12}$ we propose the plausible catalytic cycle for the transformation (Scheme 3). The first step is the formation of active catalyst species through ligand exchange with AgOAc. Next, the directed ortho $\mathrm{C}-\mathrm{H}$ activation, assisted by the weakly coordinating anilide 1 results in the rhodacycle intermediate $\mathbf{A}$. Coordination and regioselective migratory insertion (carborhodation) of the propargyl alcohol leads to the eight-membered rhodacycle intermediate $\mathbf{C}$. Reductive elimination from the intermediate $\mathbf{D}$ gives rise to the product $\mathbf{3}$. Intermediate $\mathbf{A}$ and $\mathbf{C}$ (Scheme 3) were detected in ESI-HRMS (see the SI for details).

Scheme 3. Proposed Mechanism:

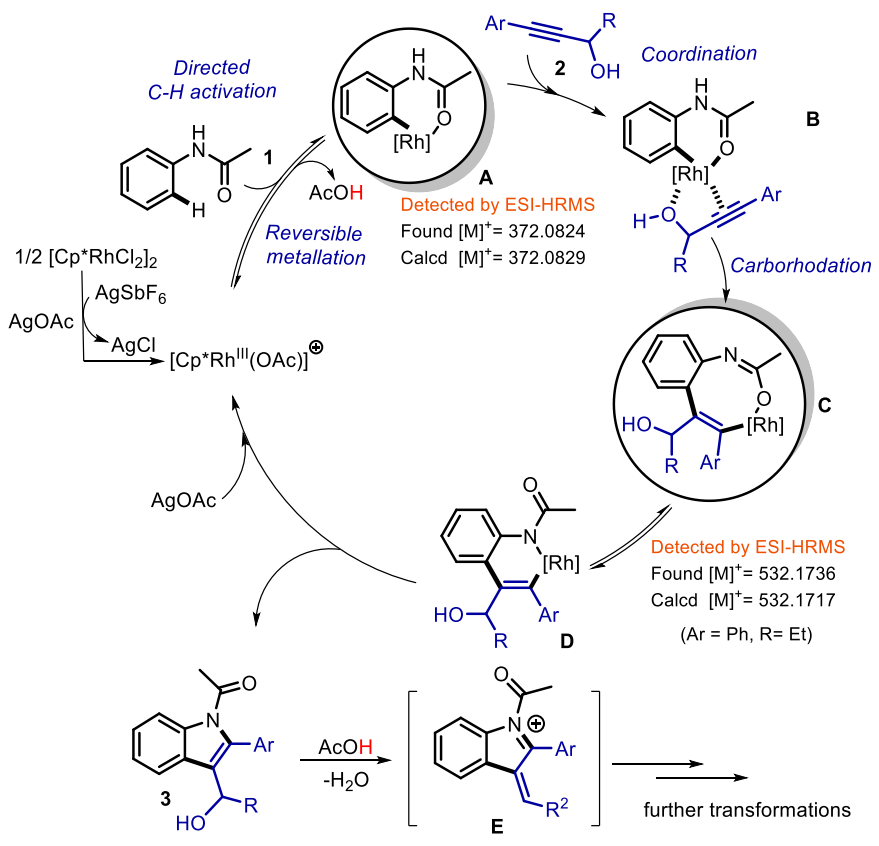

To conclude, in this work, we have presented the utilization of propargyl alcohols as three-carbon synthons wherein we have developed an unprecedented heteroannulation of indoles by merging $\mathrm{C}-\mathrm{H}$ activation and a concomitant cascade cyclization. This methodology leads to the synthesis of diverse heterocycles in a one-pot fashion. The transformation proceeds smoothly with a broad range of $\mathrm{C}-, \mathrm{N}$-, and $\mathrm{O}$ - based external nucleophiles. By choosing appropriate coupling partners, we can switch the reactivities in these substrates achieve the synthesis of $\gamma$-carbolines and dihydrochromenoindoles. The cascade process opens a synthetically novel route for the construction of the isocryptolepine derivatives, $\gamma$-carbolines and drug molecules based on these molecular frameworks. The application of this methodology in the synthesis of several indole-based alkaloids is currently in progress in our laboratory.

\section{ASSOCIATED CONTENT}

Supporting information: Experimental details and spectral data, $\mathrm{X}$ ray data of 3r, 4l, 5a and 6a. CCDC 2036753, 1987269, 2050871 and 1987690 contain the supplementary crystallographic data for this paper. These data can be obtained free of charge via www.ccdc.cam.ac.uk/data_request/cif, or by emailing data_request@ccdc.cam.ac.uk, or by contacting The Cambridge Crystallographic Data Centre, 12 Union Road, Cambridge CB2 1EZ, UK; fax: +44 1223336033 .

\section{AUTHOR INFORMATION}

\section{Corresponding Author}

Manmohan Kapur - Department of Chemistry, Indian Institute of Science Education and Research Bhopal, India.

*E-mail:mk@iiserb.ac.in

\section{ACKNOWLEDGMENT}

Funding from SERB-India (EMR/2016/004298) and CSIR-Delhi (02(0361)/19/EMR-II) is gratefully acknowledged. PJN thanks CSIR-India, for research fellowship. We thank Pravin Kumar, IISERB for solving the X-ray data. We thank the CIF, IISERB, for the analytical data and the Director, IISERB, for funding and the infrastructure facilities.

\section{REFERENCE}

(1) (a) Nicolaou, K. C.; Edmonds, D. J.; Bulger, P. G. Cascade Reactions in Total Synthesis. Angew. Chem., Int. Ed. 2006, 45, 7134 7186. (b) Ohno, H.; Inuki, S. Recent Progress in Palladium-catalyzed Cascade Cyclization for Natural Product Synthesis. Synthesis. 2017, $50,700-710$

(2) (a) Chen, J. B.; Jia, Y. X. Recent Progress in Transition-Metalcatalyzed Enantioselective Indole Functionalizations. Org. Biomol. Chem. 2017, 15, 3550-3567.

(3) (a) Dai, J.; Dan, W.; Zhang, Y.; Wang, J. Recent Developments on Synthesis and Biological Activities of $\gamma$-Carboline. Eur. J. Med. Chem. 2018, 157, 447-461. (b) Ivachtchenko, A.V.; Frolov, E. B.; Mitkin, O. D.; Kysil, V. M.; Khvat, A. V.; Okun, I. M.; Tkachenko, S. E.; Synthesis and Biological Evaluation of Novel $\gamma$-Carboline Analogues of Dimebon as Potent 5-HT6 Receptor Antagonists. Bioorg. Med. Chem. Lett. 2009, 19, 3183-3187. (c) Harbert, C. A.; Plattner, J. J.; Welch, W. M.; Weissman, A.; Koe, B. K. Neuroleptic Activity in 5aryltetrahydro- $\gamma$-Carbolines. J. Med. Chem. 1980, 23, 635-643. (d) Dejon, L.; Mohammed, H.; Du, P.; Jacob, C.; Speicher, A. Syntheis of Chromenoindole derivatives From Robinia Pseudoacaacia. Med. Chem. Commun, 2013, 4, 1580-1583. (e) Sarva, S.; Harinath, J. S.; Sthanikam, S. P.; Ethiraj, S.; Vaithiyalingam M.; Cirandur, S. R. Synthesis, antibacterial and anti-inflammatory activity of bis(indolyl)methanes. Chin. Chem. Lett., 2016, 27, 16-20.

(4) See literature for Propargyl carbonate: (a) Kumar, G. R.; Manda, R.; Lin, S.; Liu, S. Propargyl alcohol as Coupling Partner in TransitionMetal-catalyzed Arene C-H activation. Adv. Synth. Catal. 2020, 362, 5238-5256. (b) Zhu, C.; Kuniyil, R.; Ackermann, L. Manganese(I)Catalyzed $\mathrm{C}-\mathrm{H}$ Activation/Diels-Alder/retro-Diels-Alder Domino Alkyne Annulation featuring Transformable Pyridines. Angew. Chem., Int. Ed. 2019, 58, 5338-5342. (c) Zheng, G.; Sun, J.; Xu, Y.; Zhai, S.; Li, X. Mn-Catalyzed Dehydrocyanative Transannulation of Heteroarenes and Propargyl Carbonates through $\mathrm{C}-\mathrm{H}$ Activation: Beyond the Permanent Directing Effects of Pyridines/Pyrimidines. Angew. Chem., Int. Ed. 2019, 58, 5090-5094. (d) Wu, S.; Huang, X.; Wu, W.; Li, P.; Fu, C.; Ma, S. A C-H Bond Activation-based Catalytic Approach to Tetrasubstituted Chiral Allenes. Nat. Commun. 2015, 6 , 7946-7954. (e) Zhu, C.; Kuniyil, R.; Jei, B. B.; Ackermann, L. Domino $\mathrm{C}-\mathrm{H}$ Activation/Directing Group Migration/Alkyne Annulation: Unique Selectivity by $\mathrm{d}^{6}-$ Cobalt(III) Catalysts. ACS Catal. 2020, 10, 4444-4450. (f) Li, T.; Yang, Z.; Song, Z.; Chauvin, R.; Cui, X. Rhodium(III)-Catalyzed [4+3] Annulation of $N$-Aryl-pyrazolidinones and Propargylic Acetates: Access to Benzo[c][1,2]diazepines. Org. Lett. 2020, 22, 4078-4082.

(5) See Literature for Propargyl alcohol: (a) Wang, F.; Qi, J.; Zhang, X.; Li, X. Rh(III)-Catalyzed Coupling of Benzamides with Propargyl Alcohols via Hydroarylation-Lactonization. Org. Lett. 2013, 15, 6290-6293. (b) Anukumar, A.; Tamizmani, M.; Jeganmohan, M. Ruthenium(II)-Catalyzed Regioselective-Controlled Allenylation/ Cyclization of Benzimides with Propargyl Alcohols. J. Org. Chem. 2018, 83, 8567-8580. (c) Sihag, P.; Jeganmohan, M. Regioselective Synthesis of Isocoumarins via Iridium(III)-Catalyzed Oxidative 
Cyclization of Aromatic Acids with Propargyl Alcohols. J. Org. Chem. 2019, 84, 2699-2712. (d) Chen, W.; Liu, F.; Gong, W.; Zhou, Z.; Gao, H.; Shi, J.; Wu, B.; Yi, W. Hydroxyl Group-Prompted and Iridium(III)Catalyzed Regioselective $\mathrm{C}-\mathrm{H}$ Annulation of $\mathrm{N}$-phenoxyacetamides with Propargyl Alcohols. Adv. Synth. Catal. 2018, 360, 2470-2475. (e) Song, X.; Doan, B. N. D.; Zhang, X.; Lee, R.; Fan, X. Complementary $\mathrm{C}-\mathrm{H}$ Functionalization Mode of Benzoylacetonitriles: ComputerAugmented Study of a Regio- and Stereoselective Synthesis of Functionalized Benzofulvenes. Org. Lett. 2020, 22, 46-51. (f) Gong, W.; Zhou, Z.; Shi, J.; Wu, B.; Huang, B.; Yi, W. Catalyst-Controlled $[3+2]$ and $[4+2]$ Annulations of Oximes with Propargyl Alcohols: Divergent Access to Indenamines and Isoquinolines. Org. Lett. 2018, 20, 182-185. (g) Xu, Y.; Li, B.; Zhang, X.; Fan, X. One-Pot Synthesis of Fused $\mathrm{N}, \mathrm{O}$-Heterocycles through $\mathrm{Rh}$ (III)-Catalyzed Cascade Reactions of Aromatic/Vinylic $N$-Alkoxy Amides with 4-Hydroxy-2Alkynoates. Adv. Synth. Catal. 2018, 360, 2613-2620.

(6) See literature for $\beta$-Hydroxide elimination : (a) Song, X.; Gao, C.; Li, B.; Zhang, X.; Fqin, X.; Regioselective Synthesis of 2-Alkenylindoles and 2-Alkenylindole-3-carboxylates through the Cascade Reactions of $N$-Nitrosoanilines with Propargyl Alcohols. $J$. Org. Chem. 2018, 83, 8503-852. (b) Wu, S.; Wu, X.; Fu, C.; Ma, S. Rhodium(III)-Catalyzed $\mathrm{C}-\mathrm{H}$ Functionalization in Water for Isoindolin-1-one Synthesis. Org. Lett. 2018, 20, 2831-2834. (c) Wu, S.; Huang, X.; Fu, C.; Ma, S. Asymmetric $\mathrm{SN}^{2}$-type C-H functionalization of arenes with propargylic alcohols. Org. Chem. Front., 2017, 4, 2002-2007. (d) Zhang, L.; Xu, Y.; Zhang, X.; Zhang, $\mathrm{X}$; Fan, X. Synthesis of pyrazolone fused benzodiazepines via $\mathrm{Rh}(\mathrm{III})$ -catalyzed [4+3] annulation of 1-phenylpyrazolidinones with propargyl alcohols. Org. Chem. Front., 2020, 7, 2284-2290.

(7) See literature for Propargyl alcohol as one carbon synthon: (a) Wu, X.; Wang, B.; Zhou, Y.; Liu, H. Propargyl Alcohols as One-Carbon Synthons: Redox-Neutral Rhodium(III)-Catalyzed C-H Bond Activation for the Synthesis of Isoindolinones Bearing a Quaternary Carbon. Org. Lett. 2017, 19, 1294-1297. (b) Wu, X.; Wang, B.; Zhou, Y.; Zhou, Y.; Liu, H. Ruthenium-Catalyzed Redox-Neutral [4+1] Annulation of Benzamides and Propargyl Alcohols via $\mathrm{C}-\mathrm{H}$ Bond Activation. ACS Catal. 2017, 4, 2494-2499. (c) Yi, W.; Chen, W.; Liu, F.; Zhong, Y.; Wu, D.; Zhou, Z.; Gao, H. Rh(III)-Catalyzed and Solvent-Controlled Chemoselective Synthesis of Chalcone and Benzofuran Frameworks via Synergistic Dual Directing Groups Enabled Regioselective $\mathrm{C}-\mathrm{H}$ Functionalization: A Combined Experimental and Computational Study. ACS Catal. 2018, 8, 9508-9519. (d) Zhou, W.; Mei, Y.; Li, B.; Guan, Z.; Deng, Q. Synthesis of $\beta$-Alkyl 2-Hydroxychalcones by Rhodium-Catalyzed Coupling of $\mathrm{N}$-Phenoxyacetamides and Nonterminal Propargyl Alcohols. Org. Lett. 2018, 20, 5808-5812.

(8) See literature for $\mathrm{C}-\mathrm{C}$ bond cleavage and propargyl cycloalkanol: (a) Yan, X.; Ye, R.; Sun, H.; Zhong, J.; Xiang, H.; Zhou, X. Synthesis of 2-Arylindoles by Rhodium-Catalyzed/Copper-Mediated Annulative
Coupling of $N$-Aryl-2-aminopyridines and Propargyl Alcohols via Selective C-H/C-C Activation. Org. Lett. 2019, 21, 7455-7479. (b) Li, T.; Wang, Z.; Zhang, M.; Zhang, H.; Wen, T. Rh/Cu-catalyzed multiple $\mathrm{C}-\mathrm{H}, \mathrm{C}-\mathrm{C}$, and $\mathrm{C}-\mathrm{N}$ bond cleavage: facile synthesis of pyrido[2,1-a]indoles from 1 -(pyridin-2-yl)- $1 H$-indoles and $c$-substituted propargyl alcohols. Chem. Commun., 2015, 51, 6777-6780.

see related literature for propargyl cycloalkanols: (c) Hu, X.; Chen, X.; Zhu, Y.; Deng, Y.; Zeng, H.; Jiang, H.; Zeng, W. Rh(III)-Catalyzed Carboamination of Propargyl Cycloalkanols with Arylamines via C $s p^{2}-\mathrm{H} / \mathrm{Csp}^{3}-\mathrm{C} s p^{3}$ Activation. Org. Lett. 2017, 19, 3474-3477. (d) Pan, J.; Liu, C.; Chen. C.; Liu, T.; Wang, M.; Sun, Z. Zhang, S. Dual Directing-Groups-Assisted Redox-Neutral Annulation and Ring Opening of $\mathrm{N}$-Aryloxyacetamides with 1-Alkynylcyclobutanols via Rhodium(III)-Catalyzed C-H/C-C Activations. Org. Lett. 2019, 21, 8, 2823-2827. (e) Xu, Y.; Shen, M.; Zhang, X.; Fan, X. Selective Synthesis of Pyrazolo[1,2-a]pyrazolones and 2-Acylindoles via Rh(III)-Catalyzed Tunable Redox-Neutral Coupling of 1-Phenylpyrazolidinones with Alkynyl Cyclobutanols. Org. Lett. 2020, 22, 4697-4702. (f) Zhang, L.; Chen, J.; Chen, X.; Zheng, X.; Zhou, J.; Zhong, T.; Chen, Z.; Yang, Y.; Jiang, X.; She, Y.; Yu, C. Rh(III)Catalyzed, Hydrazine-directed $\mathrm{C}-\mathrm{H}$ Functionalization with 1Alkynylcyclobutanols: A New Strategy for $1 H$-Indazoles. Chem. Commun., 2020, 56, 7415-7418.

(9) For cyclization see reviews : (a) Qian, H.; Huang, D.; Bi, Y.; Yan, G. 2-Propargyl Alcohols in Organic Synthesis. Adv. Synth. Catal. 2019, 361, 3240-3280. (b) Zhu, Y.; Sun, L.; Lu, P.; Wang, Y. Recent Advances on the Lewis Acid-Catalyzed Cascade Rearrangements of Propargylic Alcohols and Their Derivatives. ACS Catal. 2014, 4, 1911-1925. (c) Sun, J.; Wang, K.; Wang, P.; Zheng, G.; Li, X. Rhodium(III)-Catalyzed Oxidative Allylic $\mathrm{C}-\mathrm{H}$ Indolylation via Nucleophilic Cyclization. Org. Lett. 2019, 21, 4662-4666.

(10) Ma. J.; Fu, H.; Zhang, L.; Wu, W.; Jiang, H.; Zhu, S. Dual catalysis: Proton/ Metal-catalysed Tendem benzofuran annulation /Carbene Transfer Reaction. Org. Lett. 2016, 18, 1322-1325. (b) Kumar, G. R.; Kumar, Y. K.; Kant, R.; Reddy, M. S.; Synthesis of benzofuranyl and indolyl methyl azides by tandem silver-catalyzed cyclization and azidation. Org. Biomol. Chem. 2016, 14, 4077-4088. (11) (a) Meyers, C.; Rombouts, G.; Loones, K. T. J.; Coelho, A.; Maes, B. U. W. Auto-Tandem Catalysis: Synthesis of Substituted $11 H$-Indolo $[3,2-c]$ quinolines via Palladium-Catalyzed Intermolecular $\mathrm{C}-\mathrm{N}$ and Intramolecular $\mathrm{C}-\mathrm{C}$ Bond Formation. Adv. Synth. Catal. 2008, 350, 465-470.

(12) (a) Zak, M.; Estrada, A. A.; Lee, S. H.; Nicolaou, K. C. Construction of Substituted $N$-Hydroxyindoles: Synthesis of a Nocathiacin I Model System. Angew. Chem., Int. Ed. 2005, 44, 37363740. (b) Staurt, D. R.; Alsabeh, P.; Kuhn, M.; Fagnou, K. Rhodium(III)-Catalyzed Arene and Alkene C-H Bond Functionalization Leading to Indoles and Pyrroles. J. Am. Chem. Soc. 2010, 132, 18326-18339. 